Article

\title{
Electrical, Mechanical, and Thermal Properties of LDPE Graphene Nanoplatelets Composites Produced by Means of Melt Extrusion Process
}

\author{
Karolina Gaska *, Xiangdong Xu, Stanislaw Gubanski and Roland Kádár \\ Department of Materials and Manufacturing Technology, Chalmers University of Technology, \\ SE 412-96 Gothenburg, Sweden; xiangdong.xu@chalmers.se (X.X.); stanislaw.gubanski@chalmers.se (S.G.); \\ roland.kadar@chalmers.se (R.K.) \\ * Correspondence: gaskak@chalmers.se; Tel.: +46-031-772-1620
}

Academic Editor: Wei Min Huang

Received: 5 December 2016; Accepted: 29 December 2016; Published: 4 January 2017

\begin{abstract}
Composites of LDPE filled with different amounts of graphene nanoplatelets (GnP) were prepared in form of films by means of precoating technique and single screw melt-extrusion using two types of screws, compression and mixing. This manufacturing process imposes strong anisotropy on the sample's morphology, in which the nanoplatelets become oriented along the extrusion direction. Such orientation of GnP in LDPE matrix is confirmed by scanning electron microscopy observations and it yields unique electrical properties. As compared to pure LDPE, significant reductions of the through-plane conductivity are found for the composites at relatively low electric fields $(<20 \mathrm{kV} / \mathrm{mm})$ at low filler concentrations. Above the field level of $20 \mathrm{kV} / \mathrm{mm}$, a crossover effect is observed that results in a strong field dependency of the conductivity where the non-linear behavior starts to dominate. Moreover, differential scanning calorimetry (DSC) results indicate a decrease in polymer crystallinity of the composite matrix with increasing filler content, whereas thermogravimetric (TG) analysis shows a slight increase in the material's thermal stability. Application of $\mathrm{GnP}$ also leads to improvement of mechanical properties, manifested by the increase of Young's modulus and tensile strength in both types of samples.
\end{abstract}

Keywords: graphene nanocomposites; low density polyethylene; field grading materials; electrical conductivity; dielectric response; mechanical properties; thermal properties

\section{Introduction}

The world is in urgent need of a modernized power grid to meet the growing demands for a reliable, cost effective, and environmentally responsible power solution. The high voltage direct current (HVDC) technology is in this respect considered as the most feasible technical and economic solution [1] where extruded polymeric high voltage cables will be widely used for electric energy transportation across seas and inland. It is expected that the HVDC cables should be able to withstand extremely high electric stresses. However, as the weakest points of the cable technology are still located in terminations and joints [2,3], a precise control of electric field distribution in these components is of a crucial importance for maintaining their reliable operation [4]. This is presently achieved by applications of field grading materials consisting of polymer composites filled with semi-conducting particles-such as $\mathrm{SiC}, \mathrm{ZnO}$, or carbon black [2,3] — and the desired nonlinear electrical conductivity is provided by percolating filler. As such characteristics appear in composites with relatively high filler loading contents, 30-40 $\mathrm{wt} \%$, their mechanical properties are negatively affected as well as manufacturing processes become more demanding due to increased viscosity and tool wear. The alternative approach is to use conductive particles of graphene for the sake of its unique electrical, thermal, and mechanical 
properties [5,6]. The main advantage is the possibility of obtaining percolation thresholds at much lower loading contents [7-9], causing graphene-based nanocomposites to attract significant scientific interest [10]. The macroscopic properties of polymer nanocomposites are mainly dependent on the interfacial compatibility of polymer and filler particles, as well as polarity match between the graphene flake surfaces and the polymer [11]. Therefore, a proper dispersion and uniform distribution are the crucial issues. However, several studies indicated that the dispersion of graphene particles in polyolefin matrices become challenging due to the interfacial incompatibility of the constituents [12] and for this reason, selection of a proper manufacturing technique is essential. There have been a number of studies discussing methods of the composite fabrication and their influence on further materials properties [13]. For example, Kim et al., reviewed methods of dispersion into polymers and summarized resulting thermal, mechanical, and electrical properties of polymers filled with thermally reduced graphite oxide [14]. Kalaitzidou et al. [15,16] also compared potentially useful methods, such as melt compounding, solution intercalation, and in situ polymerization. Also, pre-coating compounding method, applied earlier by Drzal's group $[8,17,18]$ has shown that $\mathrm{GnP}$ nanocomposites can be produced with enhanced thermal and electrical properties.

This paper focuses on electrical, mechanical, and thermal properties of nanocomposites based on low density polyethylene (LDPE) filled with graphene nanoplatelets $(\mathrm{GnP})$ and produced through the industrially attractive extrusion process. The influence of the extrusion parameters on filler dispersion and composites morphology are elucidated.

\section{Materials and Methods}

\subsection{Materials}

LDPE in the form of pellets was provided by Borealis AB (Stenungsund, Sweden). Graphene nanoplatelets originated from XG Sciences ( $x \mathrm{GnP}$ M5 nanopowder, Lansing, MI, USA). Table 1 shows the properties of these components, in which the data for graphene nanoplatelets are as per the product data sheet, whereas the parameters of LDPE were measured by means of Gel Permeation Chromatography and Differential Scanning Calorimetry (DSC, Mettler Toledo Inc., Greifensee, Switzerland).

Table 1. Basic characteristics of the low-density polyethylene and GnP nanoplatelets as a filler.

\begin{tabular}{lccc}
\hline Graphene nanoplatelets: xGnP M5 & & \multicolumn{2}{c}{ Low density polyethylene } \\
\hline Surface Area $\left(\mathrm{m}^{2} / \mathrm{g}\right)$ & $120-160$ & $M_{\mathrm{W}}$ & 91,641 \\
Average diameter $-d_{\text {ave }}(\mu \mathrm{m})$ & 25 & $M_{\mathrm{w}} / M_{\mathrm{n}}$ & 7.552 \\
Thickness $(\mathrm{nm})$ & $6-8$ & $T_{\mathrm{m}}\left({ }^{\circ} \mathrm{C}\right)$ & 110.62 \\
Density $\rho\left(\mathrm{g} \cdot \mathrm{cm}^{-3}\right)$ & 2.2 & $T_{\mathrm{c}}\left({ }^{\circ} \mathrm{C}\right)$ & 94.09 \\
\hline
\end{tabular}

\subsection{Materials Processing}

\subsubsection{Precoating Technique}

The manufacturing process of the studied specimens is illustrated in Figure 1. It follows the precoating technique used by Drzal et al. [16], where exfoliated graphene nanoplatelets coat LDPE powder. This technique is used in order to secure a good dispersion of graphene nanoplatelets during melt extrusion process.

Firstly, LDPE pellets were cryogenically grounded into powder with an average diameter of the particles of $0.5 \mathrm{~mm}$. At the same time, $\mathrm{GnP}$ nanoplatelet powder was dispersed and exfoliated in acetone in a sonication bath for $3 \mathrm{~h}(90 \mathrm{~W})$. Mixing of LDPE powder with exfoliated $\mathrm{GnP}$ was also performed in acetone, using an overhead stirrer rotating at $500 \mathrm{rpm}$ for $40 \mathrm{~min}$ until full evaporation of acetone. Such obtained masterbatches were dried in an oven at $60^{\circ} \mathrm{C}$ for $24 \mathrm{~h}$. 


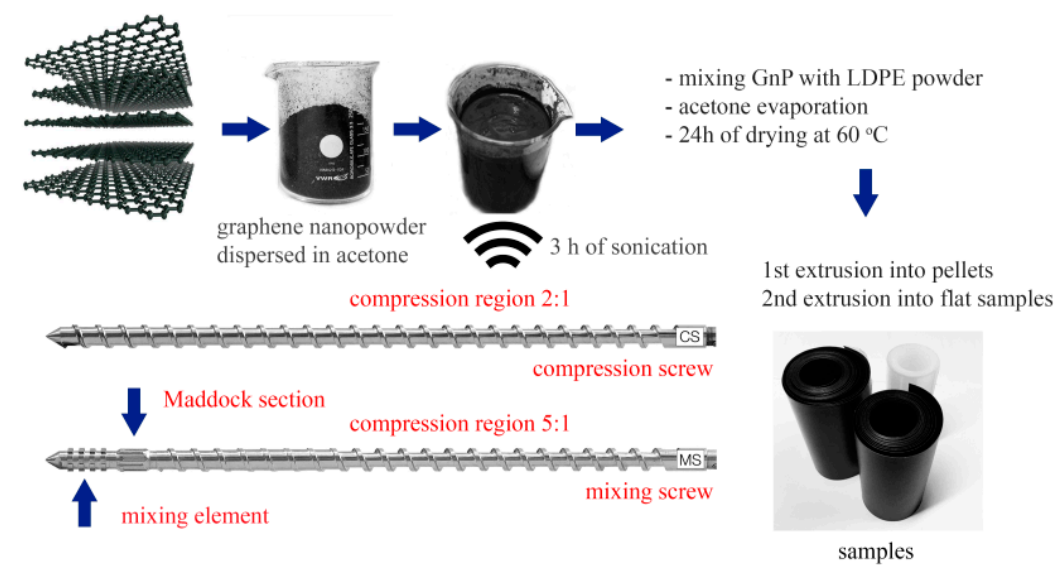

Figure 1. Scheme illustrating samples preparation process.

\subsubsection{Melt Extrusion and Film Casting}

GnP-LDPE masterbatches were extruded by means of a Brabender 19/25D (with a screw diameter $D=19 \mathrm{~mm}$ and a screw length of $25 \mathrm{D}$, Brabender GmbH \& Co, Duisburg, Germany) single-screw extruder, equipped with a conveyor belt. Two types of screws were used during the extrusion: a compression screw (CS, compression ratio 2:1) and a mixing screw (MS, compression ratio 5:1) (see Figure 1). Compression screw provides a distributive mixing, based on continuous rearrangement of composite constituents, which secures high homogeneity of the extruded material [19]. Whereas the mixing screw, equipped with a Maddock section and mixing element of specific geometry, ensures a dispersive type of mixing, in which filler particles and their agglomerates and polymer matrix are exposed to high shear stresses. It yields further improvement of filler particle distribution in samples as well as breaks agglomerated structures of filler particles [19].

The first extrusion process provided melt compounding of the produced LDPE-GnP masterbatches. During this process, only compression screw was used. The obtained material was thereafter pelletized. A second extrusion process was then used to obtain thin films of the nanocomposites with an average thickness of $0.1 \mathrm{~mm}$. The extruder temperatures from the hopper to the die were respectively: $115,130,140$, and $140{ }^{\circ} \mathrm{C}$. A constant speed of $5 \mathrm{rpm}$ was kept during the process. In total four different LDPE-GnP nanocomposite specimens were prepared, two types manufactured with compression screw (CS) and containing 1 and $5 \mathrm{wt} \%$ of GnP and two types manufactured with mixing screw (MS) also containing 1 and $5 \mathrm{wt} \%$ of GnP. In addition, pure LDPE specimens were also prepared with the same manufacturing procedure (see Table 2), which act as reference material in the following study.

Table 2. Produced samples.

\begin{tabular}{cccc}
\hline & Screw type & Filler content (wt \%) & Name of sample \\
\hline \multirow{4}{*}{ Samples } & \multirow{2}{*}{ CS } & 1 & $1 \mathrm{wt} \%$ CS \\
& & 5 & $5 \mathrm{wt} \%$ CS \\
& \multirow{2}{*}{ MS } & Pure LDPE & LDPECS \\
\cline { 2 - 4 } & & 5 & $1 \mathrm{wt} \%$ MS \\
& Pure LDPE & 1 wt \%_MS \\
& & &
\end{tabular}

\subsection{Characterization Techniques}

\subsubsection{Scanning Electron Microscopy, SEM}

The morphology of the manufactured LDPE-GnP nanocomposites was studied by means of a digital scanning electron microscope Carl Zeiss DSM 940 (Carl Zeiss AG, Oberkochen, Germany). 
The samples were cooled down in liquid nitrogen and then fractured. The analyzed surfaces were sputtered with gold in vacuum using a Sputter Coater S150B, (approximately 5-nm-thick gold layers, Edwards, Crawley, UK).

\subsubsection{Thermogravimetric Analysis, TGA}

The filler content and the thermal stability of all specimens were investigated by means of thermogravimetric analyzer, TGA/DSC 3+, Mettler Toledo, Inc., Greifensee, Switzerland. The analyses were carried out under in $\mathrm{N}_{2}$ atmosphere with a heating rate of $20^{\circ} \mathrm{C} / \mathrm{min}$. Samples of 2-5 $\mathrm{mg}$ were used, starting from $30^{\circ} \mathrm{C}$ up to $900^{\circ} \mathrm{C}$ and kept at $900{ }^{\circ} \mathrm{C}$ for $10 \mathrm{~min}$ in $\mathrm{O}_{2}$ atmosphere.

\subsubsection{Differential Scanning Calorimetry, DSC}

DSC analysis was used for defining the degree of crystallinity of the studied nanocomposites. The analyzes were performed on 2-5 mg samples using a Mettler Toledo DSC instrument. DSC scans were carried out between $-50^{\circ} \mathrm{C}$ and $150^{\circ} \mathrm{C}$ at a rate of $10^{\circ} \mathrm{C} / \mathrm{min}$ in $\mathrm{N}_{2}$ atmosphere, a heating-cooling-heating cycle was used. The degree of crystallization was calculated by the following equation:

$$
\chi_{\mathrm{c}}\left(\%_{\text {crystallinity }}\right)=\frac{\Delta H_{\mathrm{m}}}{\Delta H_{0}} * 100 \%
$$

where: $\Delta H_{\mathrm{m}}$ is the melting enthalpy, and $\Delta H_{0}$ is a theoretical value of the melting enthalpy of $100 \%$ crystalline LDPE. The value $\Delta H_{0}=293 \mathrm{~J} / \mathrm{g}$ was used in a degree of crystallinity calculations [20].

\subsubsection{Mechanical Properties}

Mechanical properties of the composites were measured by means of Instron 5567 universal testing machine (Instron, Norwood, MA, USA). Tensile tests were performed according standard ISO 37-2. Dog-bone shaped samples were cut parallel and perpendicular to the extrusion direction. All the tests were performed at room temperature and the final results being the average values of five replicated measurements.

\subsubsection{Electrical Conductivity}

The used DC conductivity measurement setup is shown in Figure 2. The setup consists of Keithley electrometer 6517B (Keithley Instruments, Solon, OH, USA). It measures the current flowing through the sample. In order to obtain conductivity values for a broad range electric fields, both the electrometer internal voltage supply (up to $1 \mathrm{kV}$ ) and a high voltage DC supply (Glassman FJ60R2, $60 \mathrm{kV}, 2 \mathrm{~mA}$ ) were used. To identify the field dependent conductivity, the measurements were performed in a way where the applied voltage was gradually increased in steps of about $4 \mathrm{kV}$ between 8 and $66 \mathrm{kV} / \mathrm{mm}$ and the duration of each step was $30 \mathrm{~min}$. All the measurements were performed at room temperature $\left(22^{\circ} \mathrm{C}\right)$. An overvoltage protection together with low pass filters were integrated into the setup in order to prevent possible instrument damage in case of specimen breakdown and for filtering out high frequency noise.

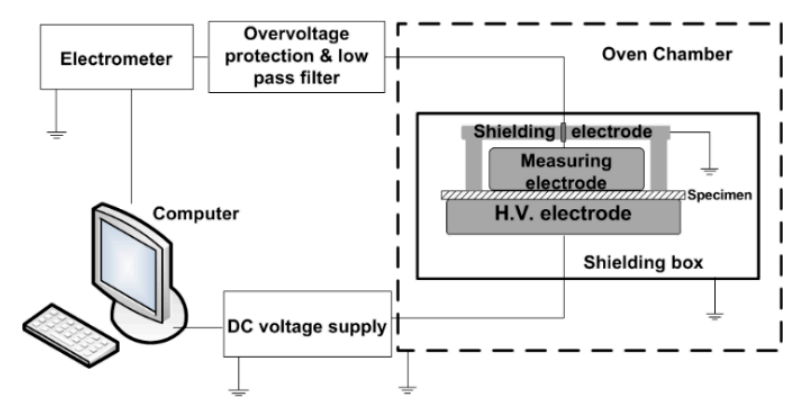

Figure 2. Schematic view of DC conductivity measurement setup. 


\subsubsection{Dielectric Response in Frequency Domain}

The dielectric response measurements were performed by IDAX 300 dielectric spectroscopy analyzer (Megger Instruments Ltd., Dover, UK) using the same shielded electrode system as described for DC conductivity measurements. The advantage of using it in the dielectric response measurements is elimination of parasitic capacitances. The measurements were performed in the frequency range of $10^{-3}-10^{3} \mathrm{~Hz}$ at room temperature $\left(22^{\circ} \mathrm{C}\right)$ at voltage level of $200 \mathrm{~V}_{\text {peak }}$.

\section{Results and Discussion}

\subsection{Morphology}

Figure $3 a, b$ show LDPE particles after the coating process. One can observe a full coverage of their surfaces with GnP nanoplatelets, GnP particles coating LDPE surface is presented on Figure 3b. Figure $3 c-f$ presents morphology of freeze-fractured samples, where the observed surfaces are perpendicular to the extrusion direction. All the figures indicate a strong anisotropy of filler alignment and uniformity of distribution of graphene flakes along polymer flow in the extrusion direction, for both types of the used screws. However, some agglomerated structures can be visible in samples extruded with compression screw (CS), whereas use of mixing screw (MS) allows avoiding this effect. This observation brings us to a conclusion that more efficient filler distribution can be obtained in samples extruded with a mixing screw equipped with a Maddock section and mixing element at its end (see Figure 1).

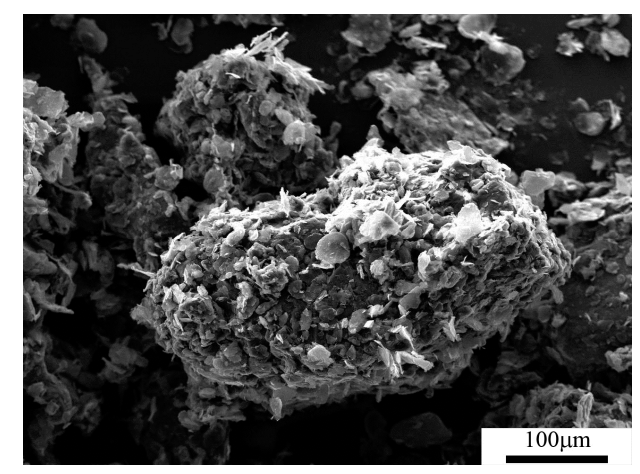

(a)

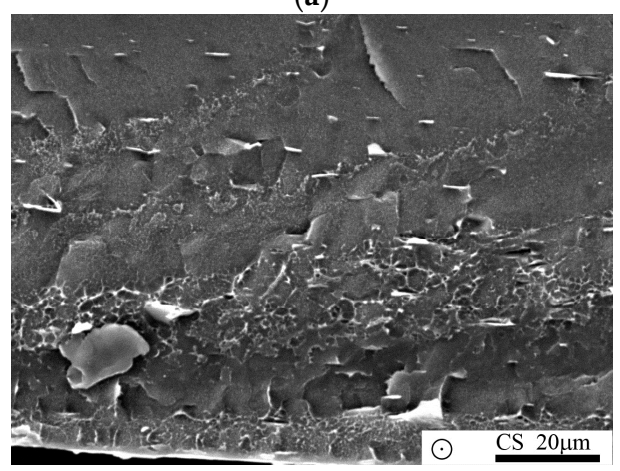

(c)

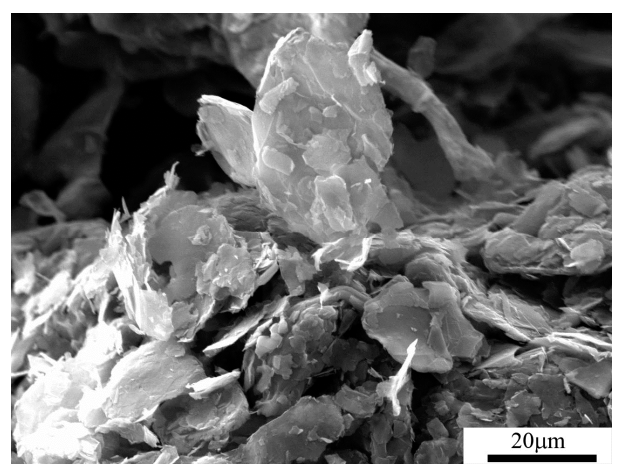

(b)

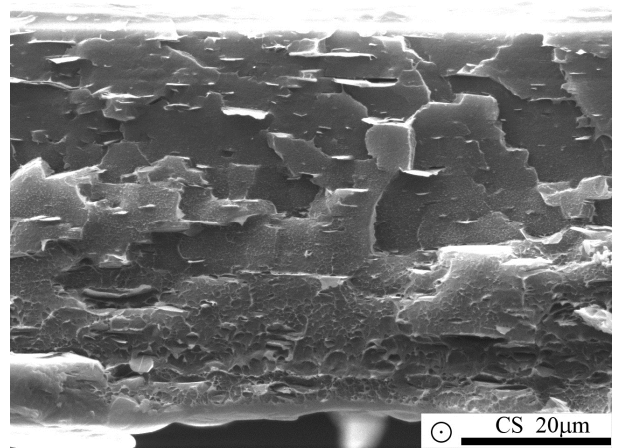

(d)

Figure 3. Cont. 


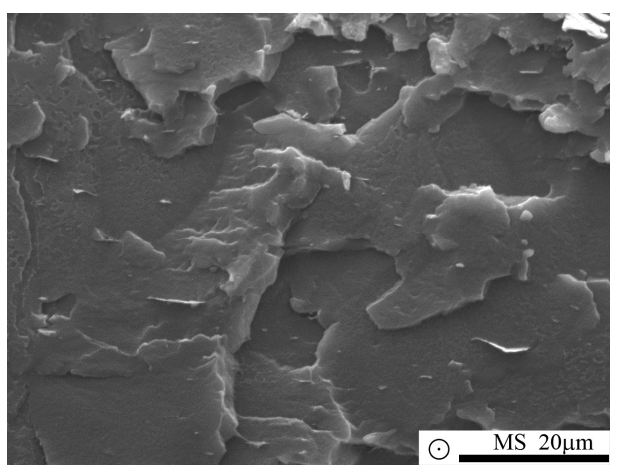

(e)

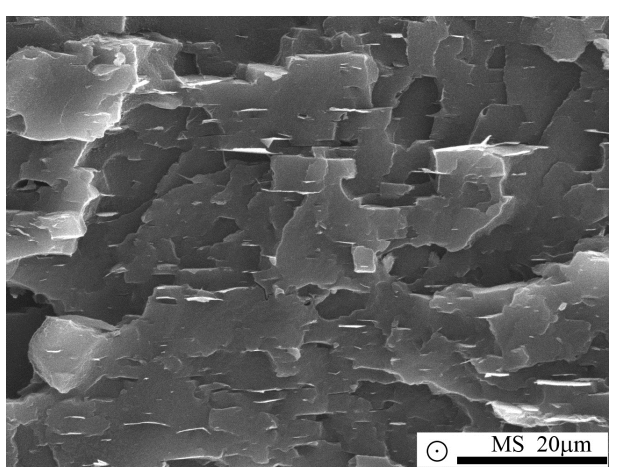

$(\mathbf{f})$

Figure 3. SEM images of LDPE powder coated with GnP nanoplatelets $(\mathbf{a}, \mathbf{b})$; freeze-fractured surfaces of nanocomposites filled with respectively $1 \%$ and $5 \%$ of GnP produced with a compression screw $(\mathbf{c}, \mathbf{d})$ and with a mixing screw $(\mathbf{e}, \mathbf{f})$. Extrusion direction is indicated by circles.

\subsection{Thermal Stability}

TGA analyses were carried out in order to confirm the content of GnP filler in the nanocomposites. TGA analysis confirmed the filling level as designed, 1.1, $4.62 \mathrm{wt} \%$ in case of samples extruded with compression screw and 1.2, $4.98 \mathrm{wt} \%$ for samples extruded with mixing screw.

The second aspect investigated was the thermal stability $T_{\mathrm{d}}$ of the nanocomposites, which is extremely important for polymeric materials and often a limiting factor in their manufacturing process and applications. The degradation temperature, defined as the temperature for $5 \%$ weight loss, has been extracted from TGA data and is presented in Figure 4.

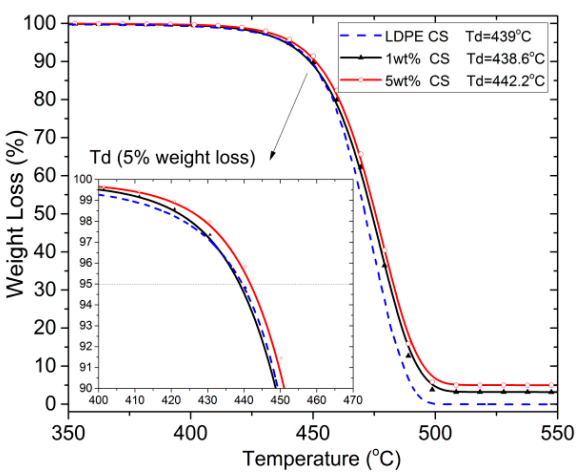

(a)

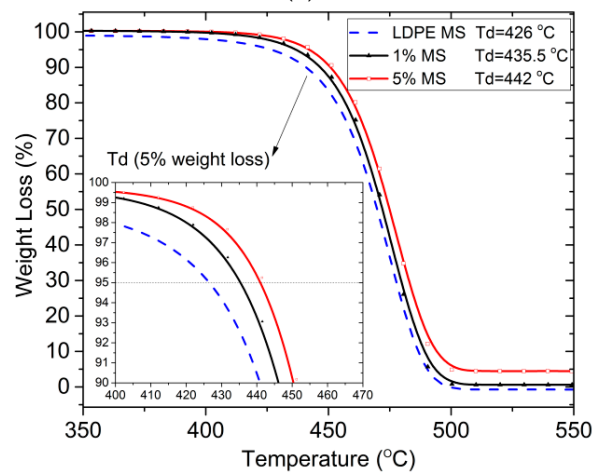

(b)

Figure 4. TGA curves measured for specimens produced with a compression screw (a) and with a mixing screw (b). 
It can be observed that thermal degradation temperature slightly increased with the increasing filler content. For pure LDPE CS samples $T_{\mathrm{d}}=439^{\circ} \mathrm{C}$, whereas for CS sample filled with $5 \mathrm{wt} \%$ of $\mathrm{GnP} T_{\mathrm{d}}=442^{\circ} \mathrm{C}$. Degradation temperature for MS samples extruded by means of mixing screw LDPE MS $T_{\mathrm{d}}=426^{\circ} \mathrm{C}$ and $5 \mathrm{wt} \%$ MS $T_{\mathrm{d}}=442{ }^{\circ} \mathrm{C}$.

\subsection{Crystallinity}

Incorporation of graphene nanoplatelets into polymer matrix is expected to impact its crystallization degree. As it was earlier observed that nucleation starts around graphite nanoplatelets [15], DSC analyses were performed here in order to investigate this behavior in GnP-LDPE nanocomposites. Table 3 presents crystallization and melting temperatures determined from DSC thermograms as well as crystallization and melting enthalpies. One can see that addition of $\mathrm{GnP}$ affects the onset temperature for crystallization $T_{\mathrm{c}}$. It decreases with increasing filler content. At the same time, the good dispersion of filler particles hinders the growth of LDPE crystallites. The crystallinity degree reduces, starting from $45.9 \%$ for pure LDPE CS sample, down to $45.94 \%$ for CS sample containing $5 \mathrm{wt} \% \mathrm{GnP}$. Crystallinity also reduces for MS samples, starting from $43.8 \%$ for pure LDPE MS sample, and going down to $39.8 \%$ for MS sample with $5 \mathrm{wt} \%$ of GnP. The effect is related to a better dispersion of filler nanoparticles in MS samples.

Table 3. Basic characteristics of the low density polyethylene and GnP nanoplatelets as a filler.

\begin{tabular}{cccccc}
\hline Sample & $\begin{array}{c}\boldsymbol{T}_{\mathrm{c}}\left({ }^{\circ} \mathrm{C}\right) \\
\text { Crystallization } \\
\text { temperature }\end{array}$ & $\begin{array}{c}\Delta \boldsymbol{H}_{\mathrm{c}}(\mathrm{J} / \mathrm{g}) \\
\text { Crystallization } \\
\text { enthalpy }\end{array}$ & $\begin{array}{c}\boldsymbol{T}_{\mathrm{m}}\left({ }^{\circ} \mathrm{C}\right) \\
\text { Melting } \\
\text { temperature }\end{array}$ & $\begin{array}{c}\Delta \boldsymbol{H}_{\mathrm{m}}(\mathrm{J} / \mathrm{g}) \\
\text { Melting } \\
\text { enthalpy }\end{array}$ & $\begin{array}{c}\chi_{\mathrm{c}}(\%) \\
\text { Crystallinity } \\
\text { degree }\end{array}$ \\
\hline LDPE-CS & 98.15 & 132.52 & 110.62 & 134.52 & 45.91 \\
LDPE_GnP_1 wt \% CS & 103.61 & 124.31 & 110.84 & 131.70 & 44.95 \\
LDPE_GnP_5 wt \% CS & 103.82 & 126.47 & 107.98 & 134.60 & 45.94 \\
LDPE-MS & 99.59 & 124.37 & 107.79 & 128.39 & 43.82 \\
LDPE_GnP_1 wt \% MS & 98.60 & 118.03 & 106.91 & 123.34 & 42.10 \\
LDPE_GnP_5 wt \% MS & 99.35 & 117.63 & 106.52 & 116.55 & 39.78 \\
\hline
\end{tabular}

\subsection{Mechanical Properties}

Nanocomposites are expected to possess enhanced mechanical properties. Efficient dispersion of filler particles and their adhesion to the base polymer are here prerequisites. Figure 5 presents stress-strain curves for neat LDPE compared with samples filled with $5 \mathrm{wt} \% \mathrm{GnP}$ content. The extrusion influence can be easily distinguished from stress-strain curves. The shear stress applied during processing leads to strong alignment of GnP flakes along extrusion direction as well as orientation of polymeric chains. One can observe in Figure 5 that maximum strain in both directions (in extrusion direction and perpendicular) decreases with increasing filler content and tensile strength increases for samples with a filler (see Figure 6). It is visible for samples manufactured by means of mixing screw, better dispersion of $\mathrm{GnP}$ leads to reduced polymer chain mobility, which reduces maximum strain especially in transverse direction.

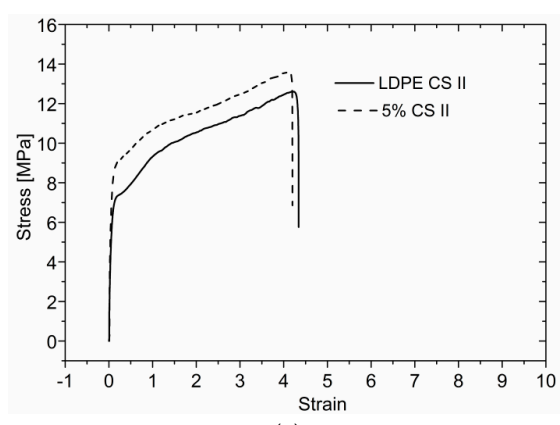

(a)

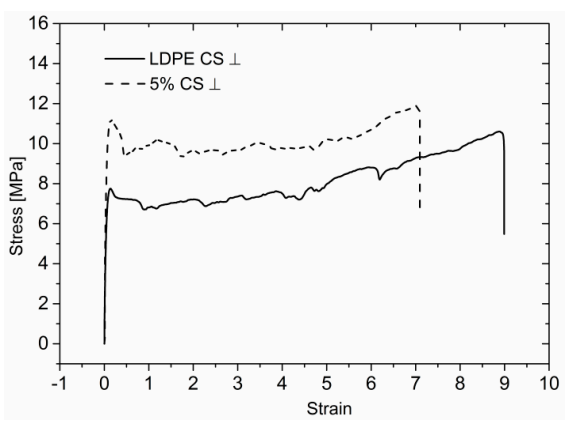

(b)

Figure 5. Cont. 


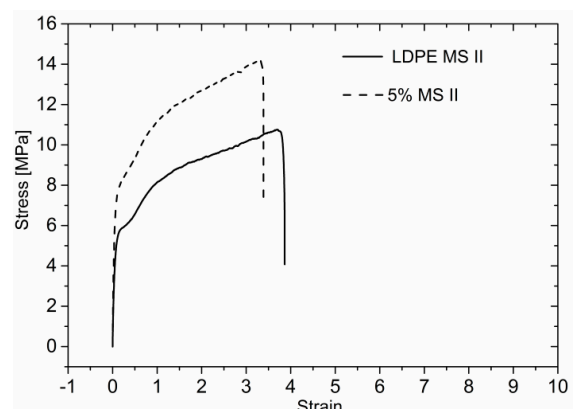

(c)

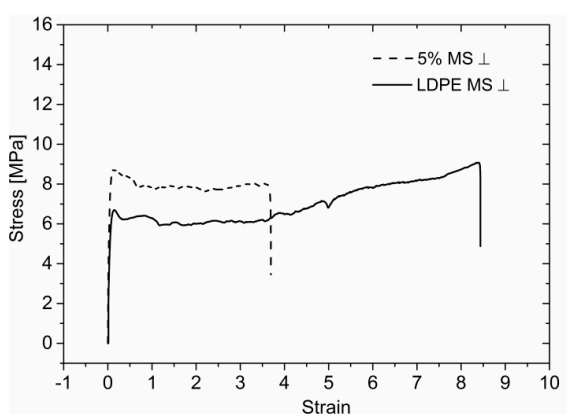

(d)

Figure 5. Stress-strain curves measured for reference sample and filled with $5 \mathrm{wt} \% \mathrm{GnP}$ (a) parallel to the extrusion CS; (b) perpendicular CS; (c) parallel to the extrusion MS; and (d) perpendicular to the extrusion.

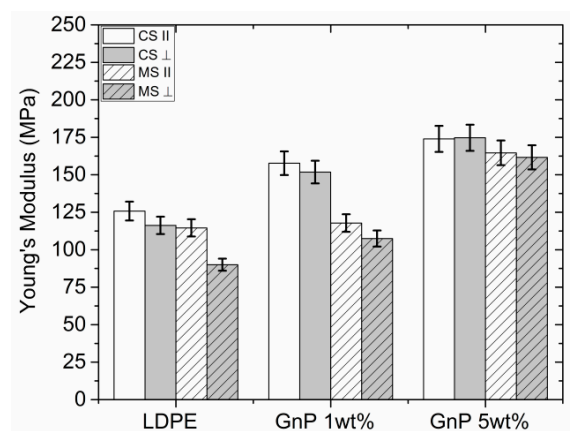

(a)

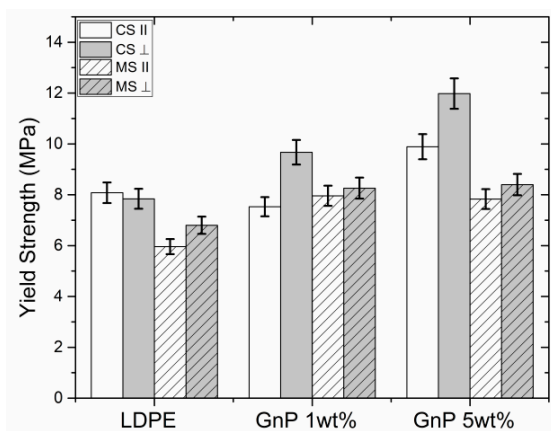

(b)

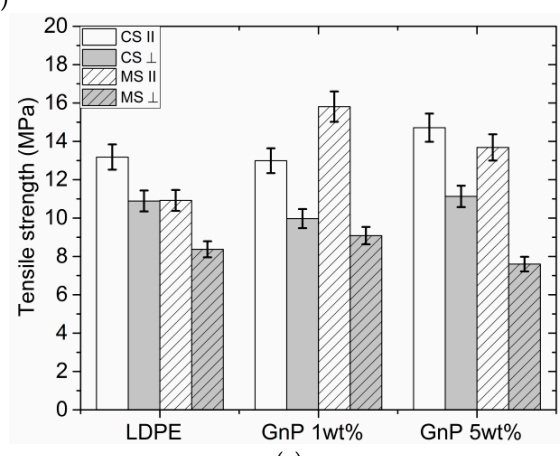

(c)

Figure 6. Comparison of Young's modulus (a); Yield strength $(\mathbf{b}, \mathbf{c})$ tensile strength for LDPE-GnP nanocomposites.

Figure 6a presents results of Young's modulus measurements for samples cut parallel and perpendicular to the extrusion direction. Figure $6 \mathrm{~b}$ represents the tensile strength of the measured nanocomposites and, thereafter, Figure 6c shows yield strength as follows. As observed in Figure 6a, Young's modulus increased for samples in both directions, the MS samples exhibit a higher Young's modulus with $79 \%$ increase for samples cut perpendicular to the extrusion direction and $43 \%$ for samples cut in parallel. Young's modulus of CS samples increased by $38 \%$ for samples cut parallel to the extrusion direction and by $50 \%$ for samples cut perpendicular. By this comparison, one can see a substantial influence of the strong anisotropy and alignment of graphene particles as well as the flow direction during the extrusion on the mechanical properties. Figure $6 \mathrm{~b}$ shows yield strength which also increased in all samples with the filler. Figure $6 \mathrm{c}$ shows the results of tensile strength tests, which stayed at the same level for all samples. The increase in mechanical properties is not significant, probably due to lack of compatibility between GnP and LDPE matrix. Therefore, surface modification and improvement of the interface is essential to increase stress transfer through 
$\mathrm{GnP}$ particles. Moreover, wrinkled and not fully exfoliated GnP surface could also have influenced the overall composite stiffness [11,14].

\subsection{Electrical Properties}

\subsubsection{Conductivity}

Figure 7 presents results of time dependence of charging current measurements, representing electrical conductivity of the investigated nanocomposites. One can observe that samples with 1 and $5 \mathrm{wt} \%$ show lower DC conductivity as compared to the reference pure LDPE. It can be assumed that $\mathrm{GnP}$ particles aligned perpendicular to the electric field act as charge trapping sites, reducing transport of electric charges through the material this way. This effect is most significant at the lower filler concentration ( $1 \mathrm{wt} \%$ ) and at a relatively low electric field. It has been already observed in several studies that introducing filler particles into LDPE matrix can significantly reduce its conductivity, when for example using nanofiller particles of $\mathrm{MgO}, \mathrm{Al}_{2} \mathrm{O}_{3}, \mathrm{SiO}_{2}$, or $\mathrm{ZnO}$ [21-25]. It has also been confirmed in [26] that introducing low concentrations of $\mathrm{GnP}$ into polyethylene reduces effective conductivity of LDPE-GnP composite. A similar behavior was reported when adding graphene oxide into polydimethylsiloxane (PDMS) matrix [27].

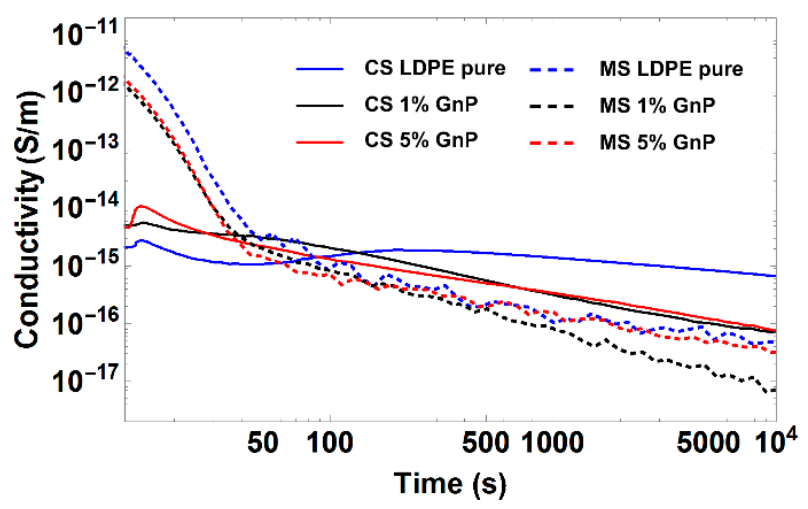

Figure 7. DC conductivity of produced nanocomposites, CS—-solid line and MS—-dashed line measured at a constant field $10 \mathrm{kV} / \mathrm{mm}$.

In Figure 8, field dependences of conductivity measured for all the investigated samples are compared. A nonlinear behavior starts to dominate this property at a field strength of about $20 \mathrm{kV} / \mathrm{mm}$. A clear crossover effect is also observed, where at low field conductivity of the filled nanocomposites turns into higher conductivity of pure LDPE CS and LDPE at higher field strength, being strongest exhibited in MS samples containing $5 \mathrm{wt} \%$ of GnP. There also seems to exist a tendency for the conduction to saturate at fields about $40 \mathrm{kV} / \mathrm{mm}$ for pure LDPE samples and above this level for the nanocomposites. A higher DC conductivity obtained for a $5 \mathrm{wt} \% \mathrm{MS} \mathrm{GnP}$ sample is a result of better dispersion of graphene nanoplatelets, as better $\mathrm{GnP}$ dispersion leads to higher DC conductivity. What is more, this behavior will correspond to the crystallinity of LDPE matrix. Samples processed with mixing screw possess lower crystallinity and this strictly corresponds to the lower tendency of charge accumulation on crystalline lamellas in an LDPE matrix. 


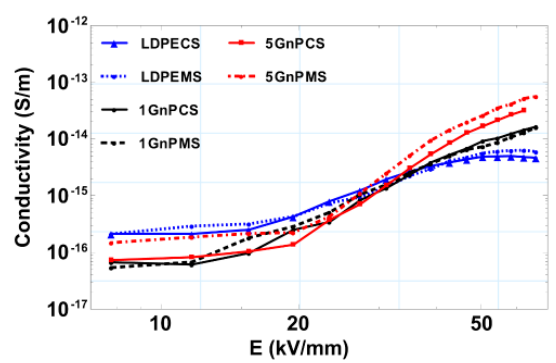

(a)

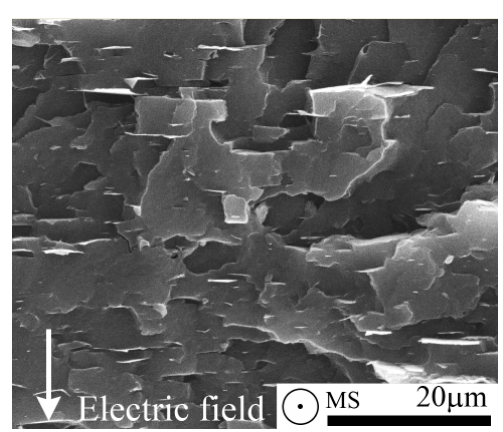

(b)

Figure 8. Field dependence of conductivity ( $30 \mathrm{~min}$ values) at $22{ }^{\circ} \mathrm{C}$ for pure LDPE and its GnP nanocomposites (a), direction of electric field (b).

\subsubsection{Dielectric Response}

Figure 9 presents dielectric variations of dielectric permittivity and dissipation factor for the investigated samples. Increases of both dielectric permittivity and losses are observed with the increasing level of GnP filler content for CS samples. In contrast, MS samples exhibit a decrease of the dielectric permittivity and the dielectric losses as compared to CS samples. This effect requires more detailed investigations as the lower permittivity and losses are beneficial in electrical insulation applications.

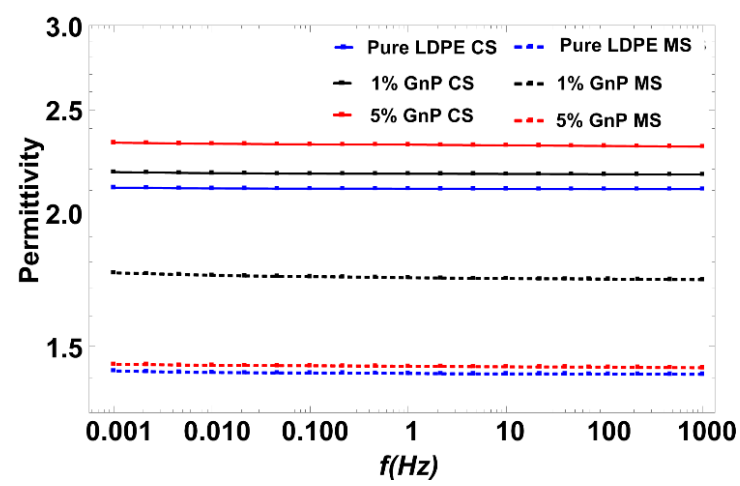

(a)

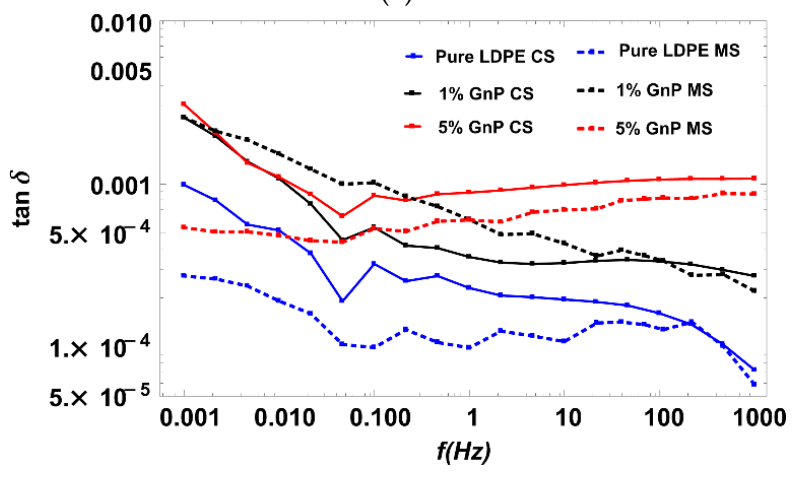

(b)

Figure 9. Dielectric response of CS vs. MS (a) dielectric constant and (b) dielectric loss.

\section{Conclusions}

It is proved by the results presented here that precoating method combined with extrusion by means of a mixing screw allows the manufacture nanocomposites of LDPE filled with 
GnP nanoplatelets that are characterized by good filler dispersion and decreased concentration of agglomerates. The extruded nanocomposites show strong anisotropy in filler distribution, which enhance their mechanical properties and yield non-linear field dependent behavior of electrical conductivity.

A lower conductivity, as compared to pure LDPE, is observed at electric field levels below $10 \mathrm{kV} / \mathrm{mm}$, while at higher fields the non-linear behavior starts dominating. It is believed that interfacial regions between LDPE and filler particles play a dominant role here by controlling space charge movement in the material bulk. On the other hand, the type of extrusion screw used for sample manufacturing affects the dielectric response characteristics of the nanocomposites differently. Increases of dielectric permittivity and dissipation factor with the increased level of GnP filler are found for samples produced with a compression screw, whereas the samples produced with a mixing screw show an opposite effect. Presented findings show that graphene nanoplatelets can be used in future applications, in which the non-linear behavior of electric conductivity is advantageous, as for example in electric field grading elements of high voltage direct current (HVDC) cable terminations and joints.

Acknowledgments: Chalmers Areas of Advance in Energy and in Nanoscience and Nanotechnology are acknowledged for financing research activities of this project. The authors are grateful to Christian Müller and Mattias Andersson for the help in DSC and TGA measurements and Mikael Rigdahl for support.

Author Contributions: Karolina Gaska manufactured samples, conducted measurements, analyzed the results, and prepared the manuscript. Xiangdong Xu performed measurements and contributed to the results analysis. Stanislaw Gubanski coordinated the work, supported the interpretation of the results, and contributed to the preparation of the manuscript. Roland Kádár helped in the sample preparation process and contributed to the analysis and interpretation of the experimental data as well as to the preparation of the manuscript.

Conflicts of Interest: The authors declare no conflict of interest.

\section{References}

1. Mazzanti, G.; Marzinotto, M. Improved design of HVDC extruded cable systems. In Extruded Cables for High-Voltage Direct-Current Transmission: Advances in Research and Development; El-Hawary, M.E., Ed.; John Wiley \& Sons, Inc.: Hoboken, NJ, USA, 2013; pp. 209-263.

2. Christen, T.; Donzel, L.; Greuter, F. Nonlinear resistive electric field grading part 1: Theory and simulation. IEEE Electr. Insul. Mag. 2010, 26, 47-59. [CrossRef]

3. Donzel, L.; Greuter, F.; Christen, T. Nonlinear resistive electric field grading part 2: Materials and applications. IEEE Electr. Insul. Mag. 2011, 27, 18-29. [CrossRef]

4. Schadler, L.S.; Wang, X.; Nelson, J.K.; Hillborg, H. Non-linear field grading materials and carbon nanotube nanocomposites with controlled conductivity. In Dielectric Polymer Nanocomposites; Nelson, K.J., Ed.; Springer: Boston, MA, USA, 2010; pp. 259-284.

5. Mittal, G.; Dhand, V.; Rhee, K.Y.; Park, S.-J.; Lee, W.R. A review on carbon nanotubes and graphene as fillers in reinforced polymer nanocomposites. J. Ind. Eng. Chem. 2015, 21, 11-25. [CrossRef]

6. Saravanan, N.; Rajasekar, R.; Mahalakshmi, S.; Sathishkumar, T.P.; Sasikumar, K.S.K.; Sahoo, S. Graphene and modified graphene-based polymer nanocomposites-A review. J. Reinf. Plast. Compos. 2014, 33, 1158-1180. [CrossRef]

7. Ariño, R.; Álvarez, E.; Rigdahl, M. Enhancing the electrical conductivity of carbon black/graphite nanoplatelets: Poly(ethylene-butyl acrylate) composites by melt extrusion. J. Appl. Polym. Sci. 2016, 133, 42897-42904. [CrossRef]

8. Jiang, X.; Drzal, L.T. Reduction in percolation threshold of injection molded high-density polyethylene/exfoliated graphene nanoplatelets composites by solid state ball milling and solid state shear pulverization. J. Appl. Polym. Sci. 2012, 124, 525-535. [CrossRef]

9. Pang, H.; Chen, T.; Zhang, G.; Zeng, B.; Li, Z.-M. An electrically conducting polymer/graphene composite with a very low percolation threshold. Mater. Lett. 2010, 64, 2226-2229. [CrossRef]

10. Das, T.K.; Prusty, S. Graphene-based polymer composites and their applications. Polym. Plast. Technol. Eng. 2013, 52, 319-331. [CrossRef] 
11. Kim, H.; Kobayashi, S.; AbdurRahim, M.A.; Zhang, M.J.; Khusainova, A.; Hillmyer, M.A.; Abdala, A.A.; Macosko, C.W. Graphene/polyethylene nanocomposites: Effect of polyethylene functionalization and blending methods. Polymer 2011, 52, 1837-1846. [CrossRef]

12. Kuilla, T.; Bhadra, S.; Yao, D.; Kim, N.H.; Bose, S.; Lee, J.H. Recent advances in graphene based polymer composites. Prog. Polym. Sci. 2010, 35, 1350-1375. [CrossRef]

13. Song, K.; Zhang, Y.; Meng, J.; Green, E.C.; Tajaddod, N.; Li, H.; Minus, M.L. Structural polymer-based carbon nanotube composite fibers: Understanding the processing-structure-performance relationship. Materials 2013, 6, 2543-2577. [CrossRef]

14. Kim, H.; Abdala, A.A.; Macosko, C. Graphene/polymer nanocomposites. Macromolecules 2010, 43, 6515-6530. [CrossRef]

15. Kalaitzidou, K.; Fukushima, H.; Askeland, P.; Drzal, L.T. The nucleating effect of exfoliated graphite nanoplatelets and their influence on the crystal structure and electrical conductivity of polypropylene nanocomposites. J. Mater. Sci. 2008, 43, 2895-2907. [CrossRef]

16. Kalaitzidou, K.; Fukushima, H.; Drzal, L.T. A new compounding method for exfoliated graphite-polypropylene nanocomposites with enhanced flexural properties and lower percolation threshold. Compos. Sci. Technol. 2007, 67, 2045-2051. [CrossRef]

17. Jiang, X.; Drzal, L.T. Improving electrical conductivity and mechanical properties of high density polyethylene through incorporation of paraffin wax coated exfoliated graphene nanoplatelets and multi-wall carbon nano-tubes. Compos. Part A Appl. Sci. Manuf. 2011, 42, 1840-1849. [CrossRef]

18. Kim, S.; Do, I.; Drzal, L.T. Thermal stability and dynamic mechanical behavior of exfoliated graphite nanoplatelets-lldpe nanocomposites. Polym. Compos. 2010, 31, 755-761. [CrossRef]

19. Osswald, T.; Menges, G. Material Science of Polymers for Engineers; Hanser Publications: Munich, Germany, 2012.

20. Borhani Zarandi, M.; Amrollahi Bioki, H. Thermal and mechanical properties of blends of LDPE and EVA crosslinked by electron beam radiation. Eur. Phys. J. Appl. Phys. 2013, 63, 21101. [CrossRef]

21. Wang, S.-J.; Zha, J.-W.; Li, W.-K.; Dang, Z.-M. Distinctive electrical properties in sandwich-structured $\mathrm{Al}_{2} \mathrm{O}_{3}$ /low density polyethylene nanocomposites. Appl. Phys. Lett. 2016, 108, 092902. [CrossRef]

22. Pallon, L.K.H.; Hoang, A.T.; Pourrahimi, A.M.; Hedenqvist, M.S.; Nilsson, F.; Gubanski, S.; Gedde, U.W.; Olsson, R.T. The impact of $\mathrm{MgO}$ nanoparticle interface in ultra-insulating polyethylene nanocomposites for high voltage dc cables. J. Mater. Chem. A 2016, 4, 8590-8601. [CrossRef]

23. Pourrahimi, A.M.; Hoang, T.A.; Liu, D.; Pallon, L.K.H.; Gubanski, S.; Olsson, R.T.; Gedde, U.W.; Hedenqvist, M.S. Highly efficient interfaces in nanocomposites based on polyethylene and $\mathrm{ZnO}$ nano/hierarchical particles: A novel approach toward ultralow electrical conductivity insulations. Adv. Mater. 2016, 28, 8651-8657. [CrossRef] [PubMed]

24. Hoang, A.; Pallon, L.; Liu, D.; Serdyuk, Y.; Gubanski, S.; Gedde, U. Charge transport in LDPE nanocomposites part I-Experimental approach. Polymers 2016, 8, 87. [CrossRef]

25. Hoang, A.; Serdyuk, Y.; Gubanski, S. Charge transport in LDPE nanocomposites part II—Computational approach. Polymers 2016, 8, 103. [CrossRef]

26. Jing, Z.; Li, C.; Zhao, H.; Zhang, G.; Han, B. Doping effect of graphene nanoplatelets on electrical insulation properties of polyethylene: From macroscopic to molecular scale. Materials 2016, 9, 680. [CrossRef]

27. Wang, Z.; Nelson, J.K.; Hillborg, H.; Zhao, S.; Schadler, L.S. Graphene oxide filled nanocomposite with novel electrical and dielectric properties. Adv. Mater. 2012, 24, 3134-3137. [CrossRef] [PubMed]

(C) 2017 by the authors; licensee MDPI, Basel, Switzerland. This article is an open access article distributed under the terms and conditions of the Creative Commons Attribution (CC-BY) license (http://creativecommons.org/licenses/by/4.0/). 